\title{
ANÁLISE GEOESTATÍSTICA DA INCIDÊNCIA DE DOENÇAS RELACIONADAS AO TRAUMA NOS BAIRROS DO MUNICÍPIO DE CAMPOS DOS GOYTACAZES
}

\section{GEOSTATISTICAL ANALYSIS OF THE INCIDENCE OF DISEASES RELATED TO TRAUMA IN THE NEIGHBORHOOD OF THE MUNICIPALITY OF CAMPOS DOS GOYTACAZES}

BATISTA, VILSON LEITE'; IGREJA, HAROLDO JOSE SIQUEIRA ${ }^{1}$; CARVALHO, BRUNO DOS SANTOS VIANA ${ }^{1}$;

PESSANHA, FELIPE EULÁLIO BALDI ${ }^{1}$; GONÇALVES, CELINO PESSANHA ${ }^{1}$; JUSTINIANO, RENATA RANGEL ${ }^{2}$; SILVA, FERNANDA MACHADO MOURA ${ }^{2}$; OLIVEIRA, PETRUCIO PESSANHA ${ }^{3}$

${ }^{1}$ Serviço de Rotina de Cirurgia Geral do Hospital Ferreira Machado.

${ }^{2}$ Residente de Cirurgia Geral da Sociedade Portuguesa Beneficente de Campos.

${ }^{3}$ Hospital Ferreira Machado

Hospital Ferreira Machado. Rua Rocha Leão, no 2 - Centro, Campos dos Goytacazes, RJ, Brasil.

Vilson Leite Batista. Rua Professor Faria, no 27 - Centro, Campos dos Goytacazes, RJ, Brasil. Tel.: (22) 99275 7757. E-mail: vilson.batista@fmc.br. 


\section{INTRODUÇÃO}

Anualmente 5,8 milhões de pessoas morrem por trauma em todo o mundo, $32 \%$ a mais que a soma das mortes por malária, AIDS e tuberculose.1 A mortalidade por trauma corresponde a $10 \%$ de todas as causas de morte e, sem as devidas intervenções, prevê-se que esta proporção aumentará até 2030. Os traumas respondem também pela maioria das incapacitações permanentes. A maior parte dos traumas ocorre entre pessoas de 5 a 44 anos, ou seja, crianças, jovens e adultos jovens.

O Hospital Municipal Ferreira Machado localizado em Campos dos Goytacazes, interior do estado do Rio de Janeiro, é a única referência da região Norte Fluminense no atendimento ao paciente Politraumatizado. Esta unidade atende em média 6 a 7 mil pacientes por mês. Sabendo do grande impacto que o trauma representa na faixa etária economicamente ativa e seu custo aos cofres públicos, realizamos um estudo geoestatístico a fim de identificar as patologias relacionadas ao trauma mais comumente encontradas nos moradores dos diversos bairros de Campos dos Goytacazes.

O objetivo do trabalho foi analisar a incidência das doenças relacionadas ao trauma nos pacientes atendidos no serviço de emergência do Hospital Ferreira Machado em Campos dos Goytacazes.

\section{MÉTODOS}

Foi realizado um estudo observacional, analítico, com todos os pacientes atendidos no Hospital Ferreira Machado, no período de janeiro de a maio de 2018. Os dados foram obtidos através de consulta aos relatórios gerados pelo software KLINICOS, utilizado em nossa unidade.

A partir desse programa foram gerados os seguintes relatórios: atendimento de emergência diagnóstico, município e bairro, estatística mensal da emergência, registro mensal de urgência por clínica e registro mensal de emergência por clínica.

A partir do relatório de atendimento de emergência diagnóstico, município e bairro, as seguintes patologias foram averiguadas: acidentes envolvendo motociclistas, acidente envolvendo ciclistas, pacientes com ferimento por arma de fogo, pacientes vítimas de agressão por arma branca e pacientes vítimas de agressão por meio de força corporal. Em seguida foi analisado a quantidade de pacientes portadores das patologias acima descritas por bairro de Campos dos Goytacazes.

Dos relatórios: estatística mensal da emergência, registro mensal de urgência por clínica e registro mensal de emergência por clínica foram analisados a quantidade de pacientes atendidos pelos seguintes setores de Clínica Médica, Oftalmologia, Ortopedia e Traumatologia, Otorrinolaringologia, Pediatria, Politrauma e Setor Laranja do HFM. Além disso, avaliamos a faixa etária dos pacientes atendidos no setor de Politrauma.

A análise descritiva foi realizada utilizando medidas de tendência central para as variáveis contínuas. Os resultados foram analisados no programa Excel onde foram desenvolvidos os gráficos. Gráficos tipo pizza para faixa etária dos pacientes atendidos no setor de Politrauma e quantidade de atendimentos por setor do HFM. Gráficos tipo barra para avaliação das doenças por bairro, apresentados em ordem decrescente. Devido à grande quantidade de bairros no gráfico de: acidentes envolvendo motociclistas, acidente envolvendo ciclistas, pacientes vítimas de agressão por arma branca e pacientes vítimas de agressão por meio de força corporal por bairro foram ocultadas os resultados menores ou iguais a 1 .

\section{RESULTADOS}

No período de janeiro a maio de 2018 foram atendidos 36.016 pacientes, destes 11051 de emergência e 24965 de urgência. O setor de Politrauma foi responsável por $26 \%$ desses atendimentos, seguido do setor de Ortopedia e Traumatologia $25 \%$ e Clínica Médica $18 \%$. Apenas no mês de março, o setor de Oftalmologia apresentou o maior número de atendimentos (2124). (Tabela 1 e 2).

Em relação à faixa etária dos pacientes atendidos no setor de politrauma, os jovens de 20 a 29 anos foram responsáveis por $22 \%$, seguido de $17 \%$ de 30 a 39 anos e $14 \%$ de 40 a 49 anos (Figura 1 ). O parque Eldorado seguido do parque Santa Rosa foram os bairros mais relacionados a pacientes vítimas de ferimento por arma de fogo (Figura 2). Em relação ás vítimas de agressão, seja por arma branca ou lesão corporal, os bairros mais incidentes foram o Jockey Club seguido do parque Prazeres (Figura 3).

Tendo em vista os acidentes envolvendo motociclistas a maioria pertencia ao bairro do Jockey Club com 19 seguido do parque Aurora e Eldorado ambos com 11 (Figura 4). Já os acidentes envolvendo 
TABELA 1 - REGISTRO DE ATENDIMENTO EMERGENCIA POR SETOR DE 01/01/2018 A $31 / 05 / 2018$

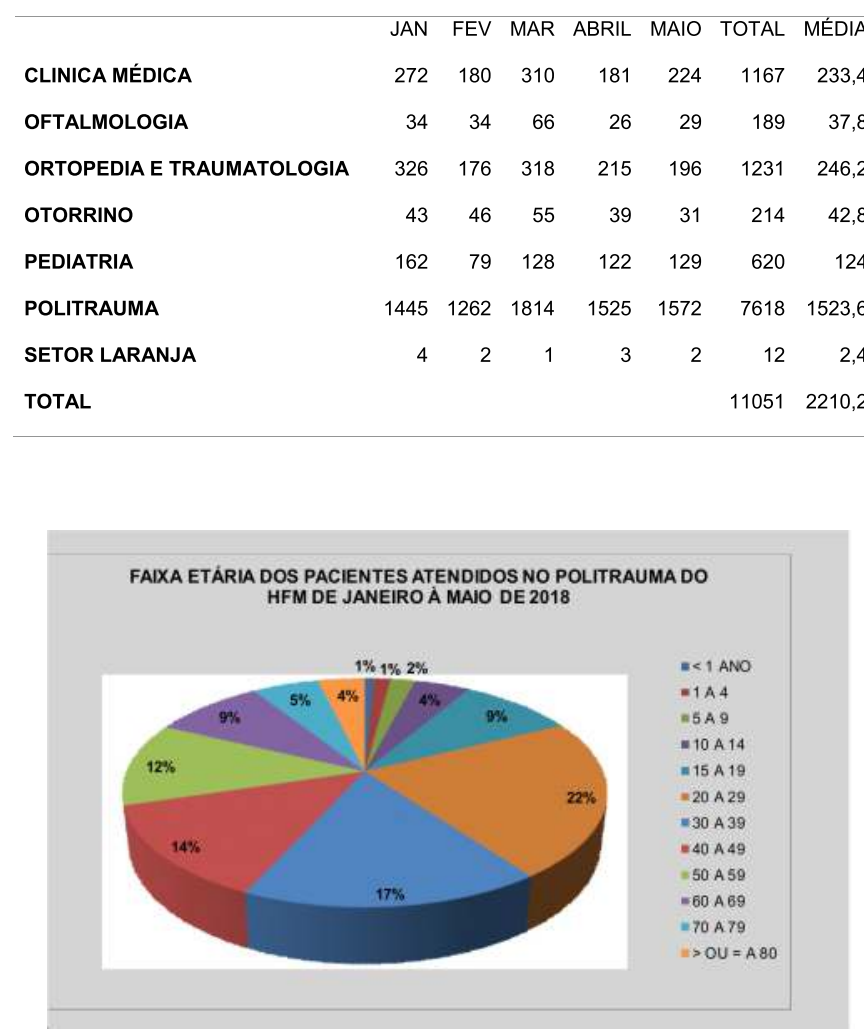

TABELA 2 - REGISTRO DE ATENDIMENTO URGÊNCIA POR SETOR DE 01/01/2018 A $31 / 05 / 2018$

\begin{tabular}{lrrrrrrr}
\hline & JAN & FEV & MAR & ABRIL & MAIO & TOTAL & MÉDIA \\
CLINICA MÉDICA & 1099 & 947 & 1053 & 1025 & 1088 & 5212 & 1042,4 \\
OFTALMOLOGIA & 454 & 609 & 2124 & 1075 & 443 & 4705 & 941 \\
ORTOPEDIA E TRAUMATOLOGIA & 1428 & 1244 & 1596 & 1721 & 1663 & 7652 & 1530,4 \\
OTORRINO & 460 & 373 & 427 & 343 & 389 & 1992 & 398,4 \\
PEDIATRIA & 606 & 489 & 770 & 945 & 905 & 3715 & 743 \\
POLITRAUMA & 374 & 410 & 292 & 295 & 303 & 1674 & 334,8 \\
SETOR LARANJA & 1 & 5 & 5 & 2 & 2 & 15 & 3 \\
TOTAL & & & & & & 24965 & 4993
\end{tabular}

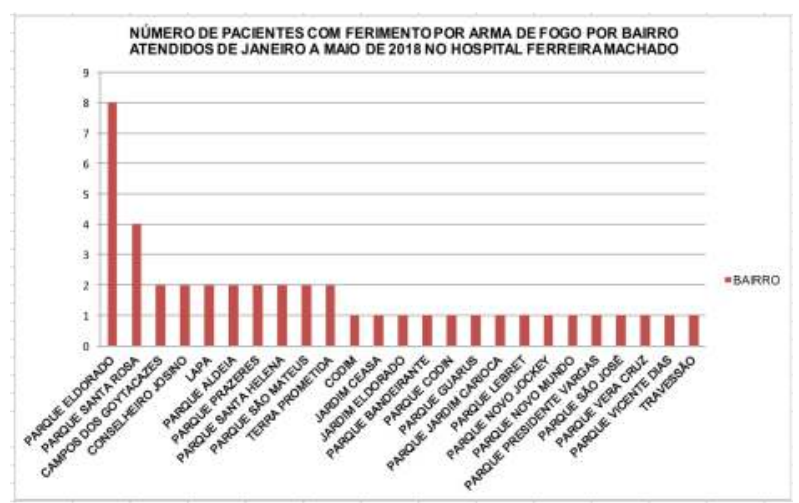

Figura 2: Ferime mato por arma de fago $x$ baimo

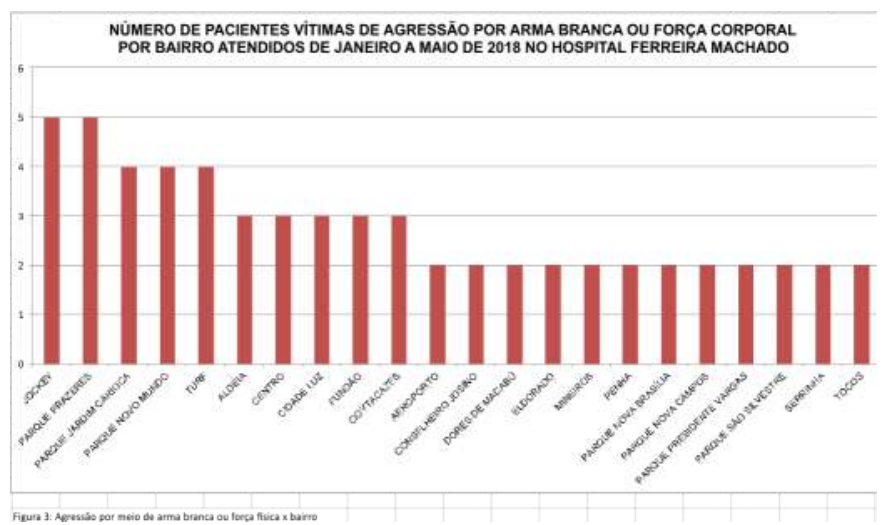


ciclistas, o bairro mais incidente foi o parque Santa Rosa com 8 seguido do Jockey com 7 (Figura 5).

\section{CONCLUSÕES}

No Brasil, a maioria dos levantamentos epidemiológicos sobre acidentes com motocicletas aponta a população de homens jovens como o principal grupo envolvido nesses eventos. Tratandose da população economicamente ativa do país, o impacto socioeconômico é alto, já que as possíveis sequelas advindas do trauma podem incapacitar esses pacientes comprometendo a qualidade de vida e eventual perda de força laborativa futura. 2 Assim como dados da OMS, verificamos que a faixa etária mais atendida no setor de Politrauma foi de jovens de 20 a 29 anos.

Apesar de serem consideradas mais ágeis e acessíveis pelo baixo custo, as motocicletas oferecem maiores riscos aos seus usuários pela maior exposição corporal.3 O bairro do Jockey Club apresentou o maior número de moradores envolvidos em acidentes motociclísticos. Além disso, este bairro encontra-se como o segundo mais incidente em acidentes envolvendo ciclista perdendo apenas para o bairro parque Santa Rosa. Trata-se do bairro que liga duas rodovias a RJ 126 Campos - Farol e a rodovia BR 356 Campos - São João da Barra. Portanto, o tráfego de veículos é praticado em alta velocidade.

Mais de $50 \%$ dos atendimentos do HFM são realizados pelos setores de Politrauma e Ortopedia. Esse dado já era esperado devido ao perfil do Hospital estudado. Vale ressaltar que no período de março de 2018 o município de Campos dos Goytacazes apresentou um surto de conjuntivite viral que foi responsável por grande número de atendimentos de oftalmologia somente neste mês.

Pela observação dos dados, tanto de atendimento de vitimas de arma de fogo quanto aos de vitimas de agressões, seja por arma branca ou força corporal, verificamos que em ambos os casos, considerando os 10 bairros mais incidentes de cada grupo, a maioria dos bairros pertencem a Guarus.

Em virtude dos dados apresentados, traçamos uma estimativa geoestatística das patologias em relação aos bairros de Campos dos Goytacazes, com o objetivo de direcionar o poder público municipal em uma abordagem mais precisa e eficaz.
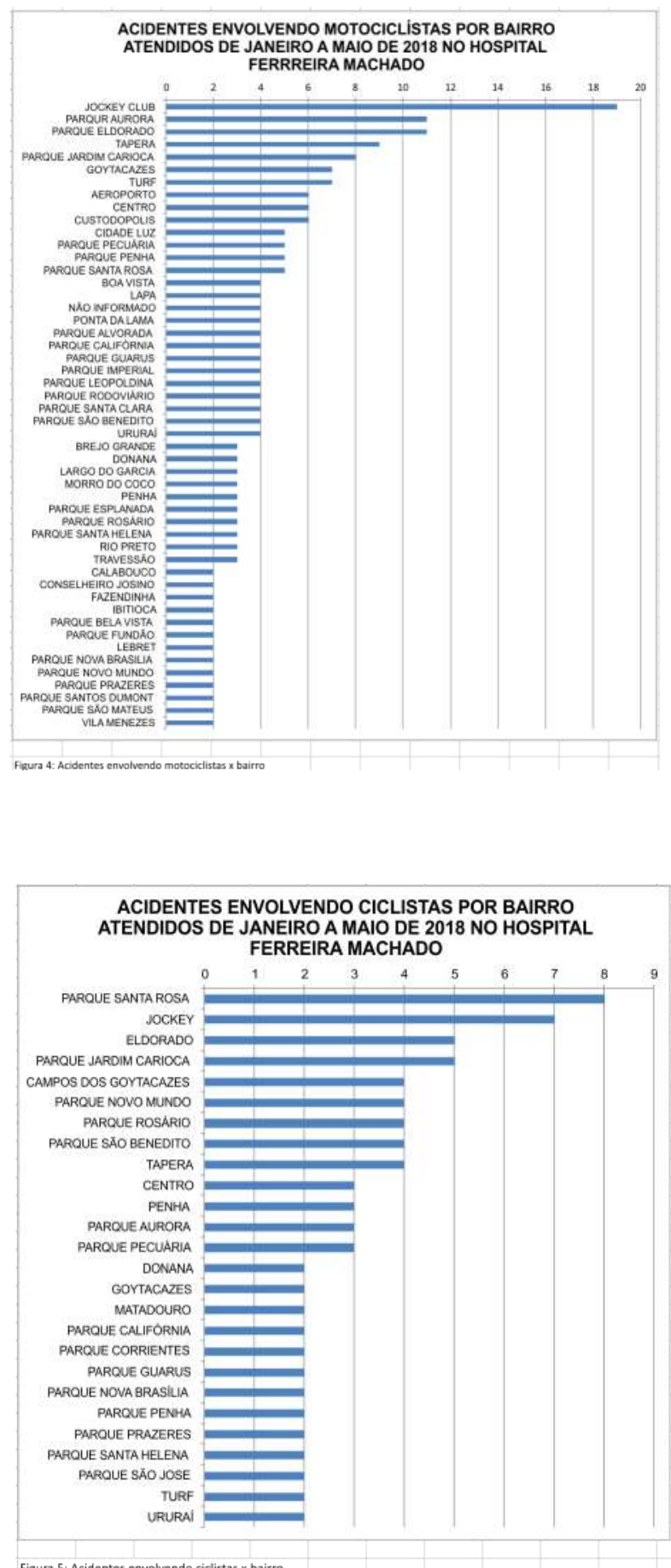

Figura 5: Acidentes envolvendo ciclistas $x$ bairro 


\section{REFERÊNCIAS BIBLIOGRÁFICAS}

1. Organização Pan-Americana da Saúde [homepage na Internet]. Brasília: acesso em 13 de junho de 2018. Anualmente 5,8 milhões de pessoas morrem por trauma em todo o mundo, $32 \%$ a mais que a soma das mortes por malária, AIDS e tuberculose. 2011. Disponível em:

https://www.paho.org/bra.../index.php?option=com_content\&view=article\&id=2989:traumas-matam-maisque-as-tres-grandes-endemias-malaria-tuberculose-e-aids\&ltemid=839 .

2. Bueno MAS, Pieri A, Sampaio RO, Santos OFP, Vaidotas M. Condutas em emergências, Unidade de Primeiro Atendimento (UPA): Hospital Israelita Albert Einstein. 1. ed. São Paulo: Editora Atheneu; 2009.

3. Simonetti FS, Cunha LO, Gurfinkel Y, Macilha TS, Campioni FC, Cabral AH, et al. Padrão de vítimas e lesões no trauma com motocicletas. Rev. Fac. Ciênc. Méd. Sorocaba. 2016; 18 (1): 36-40. 